\title{
An Anomalous Median Nerve Avoiding Injury In A Gunshot Wound To The Antecubital Fossa
}

\author{
JP Garner, BA Price
}

Maj JP Garner

MRCSEd

MRCS(Glasg) RAMC

e-mail: garners@dialstart.net

Lt Col BA Price

MD MS FRCS(Ed)

FRCS RAMC

Department of Surgery, MDHU,

Frimley Park Hospital, Portsmouth Road, Camberley, Surrey, GU16 5UJ

\begin{abstract}
We report the case of a 19 year old man who received a gunshot wound to the soft tissues of his left elbow. He presented with an ischaemic hand due to transection of the brachial artery bifurcation anterior to the elbow joint. He was spared an associated median nerve injury by an anomalous course of the nerve through the antecubital fossa.
\end{abstract}

\section{Introduction}

Penetrating extremity trauma from stab and gunshot wounds, although uncommon in UK civilian surgical practice, is on the increase. It is now becoming an important cause of vascular injury and there is a high rate of associated nerve injury. We report a case of high-energy gunshot wound traversing the antecubital fossa and dividing the brachial artery at the level of the bifurcation rendering the forearm and hand ischaemic. The patient was spared an associated median nerve injury by an unusual anatomical variation.

\section{Case Report}

A 19 year old man sustained a single highenergy gunshot wound to his left arm with a $9 \mathrm{~mm}$ entry wound on the lateral aspect of his elbow approximately $4 \mathrm{~cm}$ distal to the epicondyle exiting through a $12 \mathrm{~mm}$ exit wound below the medial epicondyle. He had absent left radial and ulnar pulses, poor capillary refill and a cool mottled hand. Sensation could not be reliably assessed because of the overt limb ischaemia. Anteroposterior and lateral X-rays of the elbow showed no bony injury but several small metallic fragments in the soft tissues
(Figures $1 \& 2$ ). In view of the limbthreatening ischaemia reflecting obvious arterial injury he was taken directly to the operating theatre for exploration and revascularisation without any attempt to delineate the injury further.

Following exposure and proximal control of the brachial artery in the arm, the injured bifurcation was identified. The radial artery was completely divided and the ulnar artery partially so with only a small part of the posterior vessel wall remaining in continuity. The fascia over the forearm muscles was opened widely to release the tense ischaemic muscles beneath. Interposition grafts of reversed native vein were used to reconstruct both divided arteries. After release of the vascular clamps good pulses were easily palpable at the wrist.

During the operation the median nerve was not identified in its usual position medially adjacent to the brachial artery in the antecubital fossa. It was assumed that the nerve had been transected by the bullet with retraction of the severed ends. The arm and forearm were thus further explored. The median nerve was identified just proximal to the flexor retinaculum and followed upward where it was seen to lie deep to the repaired vessels in the antecubital fossa, on the anterior aspect of the elbow joint capsule, beneath both heads of pronator teres (Figure 3). The nerve was uninjured throughout its course. The wounds and missile tracks were debrided, left open and dressed. The surgical wounds were closed by direct delayed primary suture four days later. The patient was discharged from hospital 14 days after his
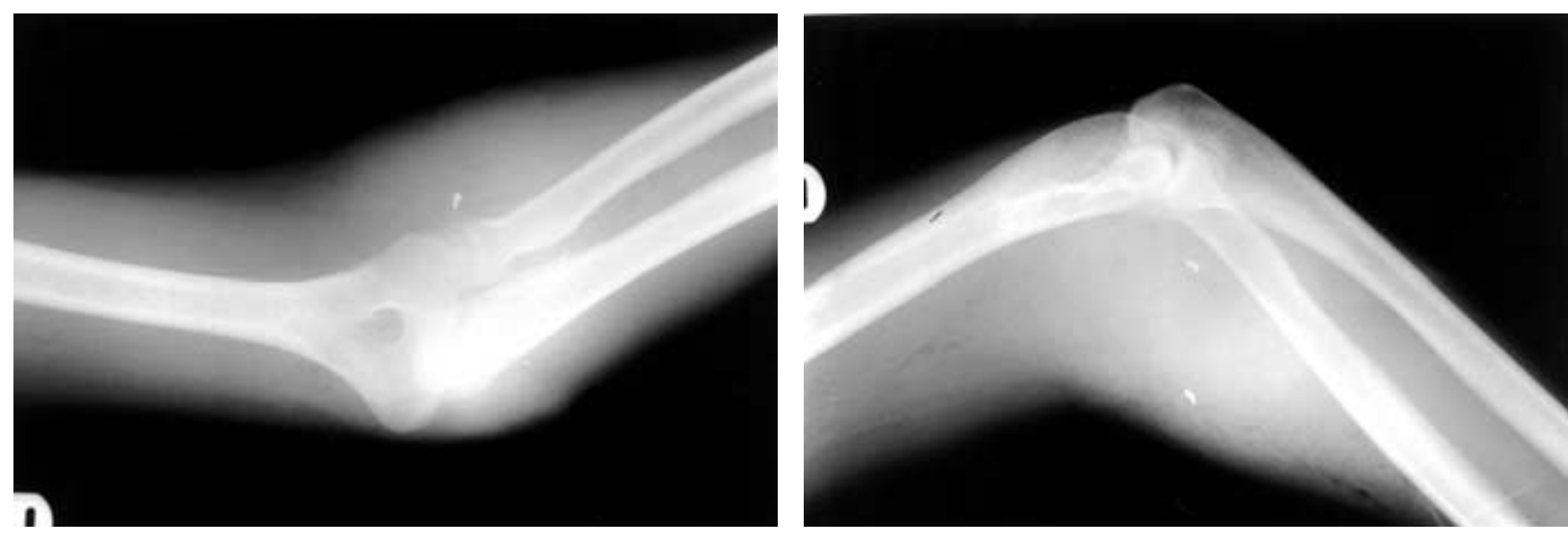

Figs 1 E⿱ 2. Anteroposterior and lateral radiographs showing metallic fragments around the elbow joint but no bony injury. 


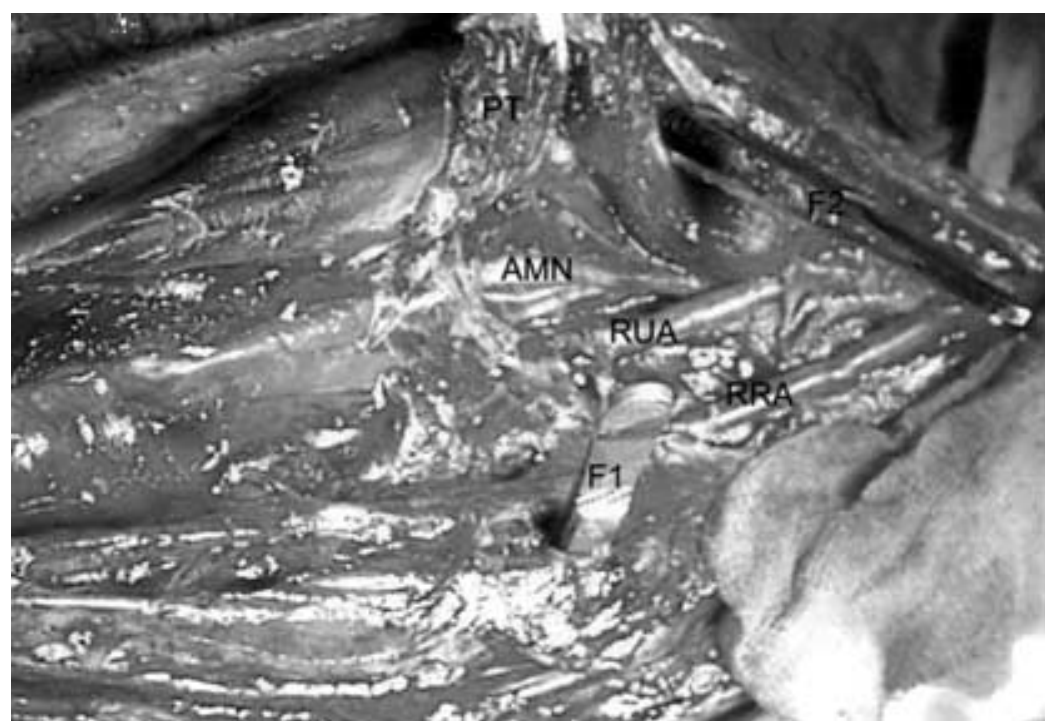

Fig 3. An operative photograph showing the anomalous median nerve (AMN) passing deep to both the reflected pronator teres (PT) muscle and the reconstituted ulnar (RUA) and radial (RRA) arteries. F1 and F2 are forceps demonstrating the missile track.

injury with excellent distal pulses and no neurological or functional deficit, confirmed at subsequent follow up.

\section{Discussion}

Penetrating trauma from stab and gunshot wounds was previously an uncommon occurrence in civilian UK surgical practice (1). In recent years there has been a rise in the number of gunshot wounds seen in some inner city UK hospitals (2) and a concomitant rise in extremity neurovascular injury. In one centre in the United States $2.5 \%$ of patients admitted with upper extremity injury had penetrating vascular trauma (3).

An acute vascular injury may be arterial, venous or both and is often found in association with injury to adjacent structures (4), particularly nerves (5). It is commonly the neurological injury that gives rise to the post-operative morbidity. One series from the United States found that $44 \%$ of patients suffering an upper limb vascular injury had a neurological deficit at time of hospital discharge and $27 \%$ had serious functional limitations (6). A separate study demonstrated that following repair of the median nerve below the axilla only $55 \%$ of patients were able to return to work (7).

A review of the literature reveals many cases of anatomical variation of the median nerve. Variations at the level of the carpal tunnel are particularly common with one operative study reporting an abnormal configuration of the median nerve in $48 \%$ of wrists studied (8). More proximal variations are less usual, but the nerve or a significant branch running anterior to the muscle belly of flexor digitorum superficialis is well described $(9,10)$. Variation of the median nerve about a ligament of Struthers, an abnormal fibrous connection between a rudimentary supracondylar spur and the medial humeral epicondyle, present in about $1.5 \%$ of cadeveric arms (11), has also been reported (12). Roberts (13) describes three cadeveric limbs in which the median nerve passed deep to the pronator teres and lay on the anterior aspect of the elbow joint medial to the trochlear. He was able to find only three other descriptions of such anomalous anatomy, none more recent than 1937. These four anatomical reports are the only previous accounts of an aberrant median nerve in the antecubital fossa, none of which have presented clinically as in this case.

The common surgical approaches to the elbow, for both open and endoscopic procedures have evolved to take safe account of the anatomy of the neurovascular structures around the joint. Aberrations of this anatomy may therefore expose patients to an increased risk of neurovascular injury at surgery and possibly also in trauma (13). Perversely, it appears that in this case the anomalous course of the median nerve saved the patient from serious neurological injury.

\section{References}

1. Magee TR, Collin J, Hands LJ, Gray DW, Roake J. A ten year audit of surgery for vascular trauma in a British teaching hospital. Eur $\mathcal{F}$ Vasc Endovasc Surg 1996;12(4):424-427.

2. Porteous MJ, Edwards SA, Groom AF. Inner city gunshot wounds. Injury 1997; 28(5-6): 385-387.

3. Pillai L, Luchette FA, Romano KS, Ricotta JJ. Upper-extremity arterial injury. Am Surg.1997; 63(3):224-7.

4. Myers SI, Harward TR, Maher DP, Melissinos EG, Lowry PA. Complex upper extremity vascular trauma in an urban population. F Vasc Surg 1990; 12(3):305-9.

5. Hardin WD Jr, O'Connell RC, Adinolfi MF, Kerstein MD. Traumatic arterial injuries of the upper extremity: determinants of disability. $A m \mathcal{F}$ Surg 1985; 150(2):266-70.

6. Borman KR, Snyder WH 3rd, Weigelt JA. Civilian arterial trauma of the upper extremity. An 11 year experience in 267 patients. Am f Surg 1984; 148(6):796-9.

7. Taha A, Taha J. Results of suture of the radial, median and ulnar nerves after missile injury below the axilla. F Trauma 1998; 45(2):335-9.

8. Stancic MF, Eskinja N, Stosic A. Anatomical variations of the median nerve in the carpal tunnel. International Orthopaedics 1995; 19: 30-34.

9. Figueirado UM, Hooper G. Abnormal course of the median nerve associated with an anomalous belly of flexor digitorum superficialis. Hand. 1980;12(3):273-4.

10. Urban T, Krosman M. Variation of the median nerve in the forearm and wrist. Folia Morphol 1992; 51(1):77-9.

11. Dellon AL. Musculotendinous variations about the medial humeral epicondyle. I Hand Surg [Br] 1986; 11(2): 175-81.

12. Gunther SF, DiPasquale D, Martin R. Struthers' ligament and associated median nerve variations in a cadaveric specimen. Yale J Biol Med1993; 66(3):203-8.

13. Roberts WH. Anomalous course of the median nerve medial to the trochlea and anterior to the medial epicondyle of the humerus. Anat Anz 1992; 174(4):309-11. 